\title{
Roselle (Hibiscus sabdariffa L.) calyx water extract ameliorates isoniazid and rifampicin induced liver and renal injuries in rats
}

\author{
Yulia Yusrini Djabir ${ }^{*}{ }^{\mathbb{D}}$, Jumasni Adnan $^{2}{ }^{\mathbb{D}}$, Nurul Amaliah $^{2}$, Nurfadilah Ramli $^{2}$, Sartini Sartini ${ }^{{ }^{\circledR}}$, Sukamto Salang

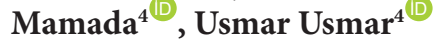 \\ ${ }^{1}$ Laboratory of Clinical Pharmacy, Faculty of Pharmacy, Hasanuddin University, Makassar, South Sulawesi, 90245, Indonesia \\ ${ }^{2}$ Faculty of Pharmacy, Hasanuddin University, Makassar, South Sulawesi, 90245, Indonesia \\ ${ }^{3}$ Laboratory of Microbiology, Faculty of Pharmacy, Hasanuddin University, Makassar, South Sulawesi, 90245, Indonesia \\ ${ }^{4}$ Laboratory of Pharmacology and Toxicology, Faculty of Pharmacy, Hasanuddin University, Makassar, South Sulawesi, 90245, Indonesia
}

\section{A R T I C L E I N F O}

Article Type:

Original Article

\section{Article History:}

Received: 23 October 2020

Accepted: 22 January 2021

\section{Keywords:}

Roselle extract

Hibiscus sabdariffa L.

Anti-tuberculosis

Hepatotoxicity

Nephrotoxicity

\begin{abstract}
A B S T R A C T
Introduction: Roselle (Hibiscus sabdariffa L.) calyces possess natural antioxidants that may provide therapeutic benefits. This study aimed to investigate the protective effects of Roselle calyx water extract against isoniazid (INH) and rifampicin (RIF) induced liver and renal toxicities.

Methods: Male Wistar rats (150-250 g) were designated into five groups: control group, INHRIF group that was treated with INH-RIF at the toxic doses $(50-100 \mathrm{mg} / \mathrm{kg}$ for 4 weeks, followed by $100-200 \mathrm{mg} / \mathrm{kg}$ for 2 weeks), and Roselle groups that were treated daily with Roselle extract at the doses $62.5,125$, and $250 \mathrm{mg} / \mathrm{kg}$, respectively prior to INH-RIF administration. Blood samples were withdrawn weekly for 6 weeks before removing rats' livers and kidneys for tissue malondialdehyde (MDA) and histopathological analysis.

Results: The results showed all rats in the INH-RIF group experienced marked elevations of serum alanine aminotransferase (ALT), aspartate aminotransferase (AST), urea, creatinine, and tissue MDA levels compared to the controls $(P<0.05)$. In contrast, these biomarkers were maintained at near-normal levels in Roselle extract groups. Significant inflammation and cellular degeneration were found in the liver and renal tissues of the INH-RIF group, which were noticeably reduced with Roselle extract pre-treatment at the dose of $250 \mathrm{mg} / \mathrm{kg}$.

Conclusion: It is concluded that Roselle calyx extract can provide protection against liver and renal toxicities induced by INH-RIF administration in rats.
\end{abstract}

Implication for health policy/practice/research/medical education:

Isoniazid (INH) and rifampicin can induce organ toxicities in tuberculosis patients upon receiving the regimen. The results of this study showed the promising protective effects of Roselle (Hibiscus sabdariffa L.) extract on liver and renal functions and histological structures in an animal model that received INH and rifampicin toxic doses. The results may be translated in clinical application to protect against nephrotoxicity and hepatotoxicity in tuberculosis patients.

Please cite this paper as: Djabir YY, Adnan J, Amaliah N, Ramli N, Sartini S, Mamada SS, Usmar U. Roselle (Hibiscus sabdariffa L.) calyx water extract ameliorates isoniazid and rifampicin induced liver and renal injuries in rats. J Herbmed Pharmacol. 2021;10(3):296-303. doi: 10.34172/jhp.2021.34.

\section{Introduction}

In recent decades, natural antioxidants from plants have received more attention as they hold great promise to be less expensive alternatives to synthetic antioxidants (1). Roselle (Hibiscus sabdariffa L., family Malvaceae) is a tropical shrub that has been traditionally utilized for medicinal purposes or simply as food or beverage coloring (2). The vibrant color and high dietary fiber content of
Roselle flowers have attracted the interest of many food industries to develop natural coloring and functional foods from Roselle extract (3). In addition, several therapeutic benefits of Roselle extract have been reported, including antibacterial activity (4), anti-hypercholesterolemia and anti-atherosclerotic properties (5), as well as antidiabetic effects (6). Moreover, the antioxidant activities of Roselle calyx aqueous extract have been reported to elicit 
protection against drug or chemical-induced liver injuries $(7,8)$.

Roselle flowers, particularly the calyces, contain a significant amount of simple phenolic and flavonoid-like polyphenol compounds, including protocatechuic acid, eugenol, anthocyanins, anthocyanidins, and flavonol quercetin (9). The anthocyanins and protocatechuic acid contents are of particular importance since they possess potent antioxidant capacities (10). The phenolic contents are soluble in polar solvents; hence, water has become one of the most important extraction mediums to isolate anthocyanin (11).

Tuberculosis (TB) is an infectious disease that is instigated by the bacteria Mycobacterium tuberculosis. In 2017 alone, approximately 1600000 people died from TB around the world, making it one of the deadliest communicable diseases in Asian and African regions (12). The management of TB infection is reliant on antituberculosis (AT) regimen administered in combination to prevent multidrug resistance and to provide complete termination of Mycobacterium tuberculosis (13).

Unfortunately, the principal AT drugs, isoniazid (INH) and rifampicin (RIF), are among the major causes of drug-induced liver injury, with the number of incidents being $18.2 \%$ to $24.6 \%(14,15)$. The toxicity of INH is predominantly mediated by its toxic metabolites, acetyl hydrazine and hydrazine, which are readily oxidized to form free radicals (16). Meanwhile, RIF toxicity is associated with its modulation on the cytochrome P450 enzyme activities, especially CYP2D6 and CYP3A4, which may amplify INH toxic metabolite formation. Thus, if these two drugs are combined, it increases the risk of hepatotoxicity (17).

It has been reported that the administration of INH $50 \mathrm{mg} / \mathrm{kg}$ and RIF $100 \mathrm{mg} / \mathrm{kg}$ can cause extensive liver damage in experimental animals $(18,19)$. Moreover, a similar dose of INH-RIF combination is also found to induce nephrotoxicity in rats (20). This toxic effect was also associated with their active metabolites, which trigger the formation of reactive oxygen species (ROS) (21). Since oxidative stress is the main cause of INH-RIF-induced organ toxicities, it is hypothesized that Roselle's natural antioxidants could prevent or reduce the detrimental effects of INH-RIF. Therefore, this study aimed to investigate the protective effects of Roselle water extract against INH-RIF-induced liver and renal toxicities in Wistar rats.

\section{Materials and Methods}

Sample collection

Roselle (Hibiscus sabdariffa L.) calyces were collected from Roselle plants cultivated in the area of Hasanuddin University, Makassar, South Sulawesi, Indonesia. The samples have been identified in the Pharmacognosy Laboratory of Hasanuddin University, where the voucher specimen was already collected. The authentication number is No.65/lab farmakognosi/DT/IV/2020. Only the bright red calyces were used as samples. The samples were washed and sorted from contaminants and subsequently dried using a fruit dryer at $50^{\circ} \mathrm{C}$ for 8 hours before pulverized using a blender. The pictures of Roselle plants and dried calyces used as samples are illustrated in Figure 1.

\section{Roselle water extraction}

Roselle water extract was prepared according to the method described in Harbourne (22) study. A total of $25 \mathrm{~g}$ of Roselle calyx powder was boiled with $100 \mathrm{~mL}$ of distilled water (the ratio of 1:4) in a water bath at $90^{\circ} \mathrm{C}$ for 15 minutes. The extract was filtered through a piece of cheesecloth. Maltodextrin was added into the filtered infusion (1:40) and freeze-dried to form a Roselle powder matrix. It is believed that the addition of maltodextrin may improve the preservation of anthocyanin and polyphenol content, as well as the antioxidant capacity of the Roselle extract powder (23).

\section{Drugs and chemicals}

INH and RIF tablets were obtained from a pharmaceutical company in Indonesia (Kimia Farma, Makassar). Diagnostic kits, such as alanine aminotransferase (GPT or ALAT) (IFCC mod. liquid UV), aspartate aminotransferase (GOT or ASAT) (IFCC mod. liquid UV), serum urea (urea liquicolor) and serum creatinine (creatinine liquicolor), were supplied from Human Diagnostic Worldwide $^{\circledR}$ (Germany) through a local distributor. All other chemicals, including diethyl ether, 2-thiobarbituric acid (Sigma Aldrich), trichloroacetic acid (Sigma Aldrich), 1-1-3-3 tetramethoxypropane (TMP) were purchased from registered chemical stores in Makassar, Indonesia.

\section{Animals}

A total of 25 male Wistar rats (150-250 g) were obtained from a registered rodent breeding facility (UD Wistar, Yogyakarta, Indonesia). The animals were then cared in the Laboratory of Pharmacology and Toxicology, Faculty of Pharmacy, Hasanuddin University, where the experiment was conducted. Animals were caged in groups of five and had free access to water and standard

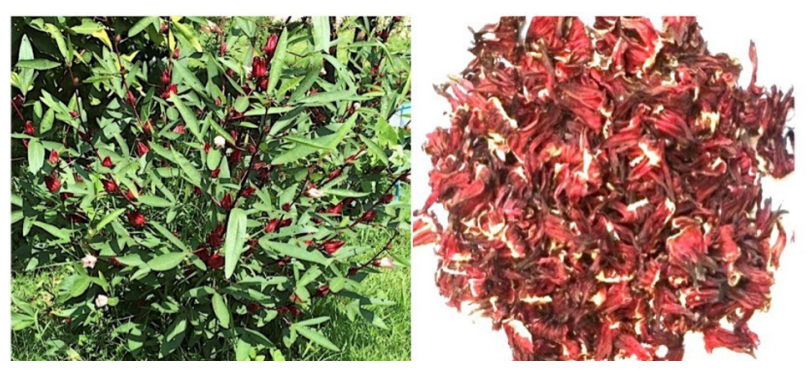

Figure 1. Roselle plant (Hibiscus sabdariffa L) (A) and dried Roselle calyces (B). 
rodent pellets. All rats were adapted to the laboratory environment with a 12-hour dark-light cycle around 2 weeks before commencing the experiment.

\section{Study protocols}

Following acclimatization, the rats were anesthetized with diethyl ether and blood sampling $(3 \mathrm{~mL})$ was performed from the lateral tail vein. The blood samples were collected in vacuum tubes containing an anticoagulant. The blood samples were then analyzed using Humalyzer 3500 (Human Diagnostic Worldwide, Germany) to obtain baseline plasma biomarkers.

The rats were weighed prior to the administration of treatments to ensure the accuracy of the dose given. The Roselle extract was freshly prepared in a suspension using $1 \%$ sodium carboxymethyl cellulose before administration. The rats were randomly assigned to one of five treatment groups $(n=5)$. The control group only received placebo; the INH-RIF group received an oral dose of INH and RIF co-treatment; Roselle treatment groups received different doses of Roselle extract $(62.5 \mathrm{mg} / \mathrm{kg}, 125 \mathrm{mg} / \mathrm{kg}$, and 250 $\mathrm{mg} / \mathrm{kg}$ ) followed by INH-RIF administration. Rat blood samples were withdrawn every week to monitor the development of the liver and renal injuries.

The initial dose of INH used in this study was $50 \mathrm{mg} /$ $\mathrm{kg}$ and RIF was $100 \mathrm{mg} / \mathrm{kg}$ to induce liver damage (24). However, the administration of INH-RIF at those given doses was found inadequate to induce the elevation of renal injury markers in this study after 28 days of treatment. Therefore, the doses of INH and RIF were adjusted to $100 \mathrm{mg} / \mathrm{kg}$ and $200 \mathrm{mg} / \mathrm{kg}$, respectively. The treatments were continued for another 14 days, making the total experimental period 42 days (6 weeks). After 24 hours from the last treatment, blood samples were withdrawn and the rats were euthanized by cervical dislocation before removing the liver and kidneys for tissue malondialdehyde (MDA) and histopathological analyses.

\section{Serum biomarker analysis}

The blood samples were collected in 3-ml vacuum tubes $\left(\mathrm{BD}^{\circledR}\right.$ vacutainer) and centrifuged for 10 minutes at 3000 rpm. The supernatant $(100-\mu \mathrm{L})$ was prepared based on the kit instructions. All biomarker levels were analyzed using Humalyzer 3500 (Human Diagnostic Worldwide ${ }^{\circledR}$, Germany) based on manufacturer instructions.

Tissue malondialdehyde analysis

Immediately after harvest, the liver and the kidneys of the rats were washed in a cold normal saline solution, then immersed in liquid nitrogen and stored in a freezer $\left(-80^{\circ} \mathrm{C}\right)$ until analyzed. The tissue MDA level was measured with a thiobarbituric acid reactive substance (TBARS) method using a spectrophotometer UV-visible at $532 \mathrm{~nm}$.

Organ histopathological assay

After washed, the liver and kidneys were fixed with Buffered Neutral Formalin (BNF) for 48 hours. The tissues were cut into $0.5-1 \mathrm{~cm}$ specimens, placed in cassettes, and processed using a tissue processor (Thermo Scientific ${ }^{\circledR}$ ). The specimen was embedded in paraffin blocks and sliced into 5 - $\mu \mathrm{m}$ thickness using a microtome. The sliced tissues were separated from the paraffin wax by floating out at $40^{\circ} \mathrm{C}$. The tissue sections were subsequently mounted onto slides, dried with an oven at $60^{\circ} \mathrm{C}$ for 2 hours, and stained using hematoxylin and eosin (H\&E). The sections were observed under a light microscope $\left(\right.$ Olympus ${ }^{\circledR}$ ) at $\times 100$ and $\times 400$ magnification. The histopathological analysis was performed by a veterinary pathologist blinded to the treatment groups. The histopathological parameters observed included cellular degeneration, necrotic cells, inflammatory cells, and tubular degeneration. The histopathological scoring was carried out semiquantitatively according to the methods explained in Shackelford report (25) as summarized in Table 1.

\section{Statistical analysis}

The normal distribution of the data was analyzed using the Kolmogorov-Smirnov test. Data analysis was performed using a one-way ANOVA followed by Tukey's HSD to determine a significant difference between treatment groups. In addition, a paired $t$ test was also used to compare the baseline and post-treatment levels of biomarkers within a group. A significant difference was defined if the $P$ value was $<0.05$.

Table 1. The criteria of damage and severity grading of histopathological changes found in the liver and renal tissues

\begin{tabular}{lll}
\hline Criteria of damage & Severity grading & The degree of histopathological changes \\
\hline Minimal & + & $\begin{array}{l}\text { Histological changes barely manifest or considered minor affecting }<10 \% \text { of the observed area at } \\
\times 400 \text { magnification }\end{array}$ \\
Mild & $+\begin{array}{l}\text { Histological changes were noticeable but not prominent, affecting } 11-20 \% \text { of the observed area at } \\
\times 400 \text { magnification }\end{array}$ \\
Moderate & $+\begin{array}{l}\text { Histological changes were noticeable and mostly prominent affecting } 21-40 \% \text { of the observed area } \\
\text { at } \times 400 \text { magnification }\end{array}$ \\
Marked & $\begin{array}{l}\text { Histological changes were diffused and overriding the healthy tissue affecting } 41-100 \% \text { of the } \\
\text { observed area at } \times 400 \text { magnification }\end{array}$
\end{tabular}

Modified from Shackelford et al (25) severity grading scheme. 


\section{Results}

Baseline levels of liver and renal biomarkers

Prior to treatment, the individual animals exhibited normal levels of alanine aminotransferase (ALT) ranging from 12.62 to $59.32 \mathrm{U} / \mathrm{L}$, aspartate aminotransferase (AST) from 40.12 to $114.2 \mathrm{U} / \mathrm{L}$, serum urea from 15.75 to $51.23 \mathrm{mg} / \mathrm{dL}$, and creatinine from 0.240 to $0.646 \mathrm{mg} /$ dL. Table 2 exemplifies the mean of baseline values of liver and renal function parameters in rats randomized to receive different treatments. No significant difference was found in all biomarker levels between groups.

Liver and renal serum biomarkers and malondialdehyde level following treatments

As illustrated in Figure 2, after 42 days of treatments, there was a significant increase in the ALT and AST levels of the INH-RIF group, which were twice as much as those of the control group $(P<0.05)$. Along with ALT and AST elevation, the renal biomarkers of the INH-RIF group were also significantly escalated, especially the urea levels, which almost tripled from the control's urea level $(P<0.05)$. The creatinine level of the INH-RIF group raised from $0.409 \pm 0.028 \mathrm{mg} / \mathrm{dL}$ at baseline to $0.671 \pm$ $0.033 \mathrm{mg} / \mathrm{dL}$ after treatment, which was significantly different from the creatinine level in the control group after treatment $(0.408 \pm 0.010 \mathrm{mg} / \mathrm{dL})$. It was found that the administration of Roselle water extract before INHRIF treatment was able to inhibit the upsurge of the liver and renal biomarkers measured. The Roselle extract treatment at the doses of 62.5 to $250 \mathrm{mg} / \mathrm{kg}$ were able to maintain the ALT, urea, and creatinine levels close to their baseline levels. However, the low dose $(62.5 \mathrm{mg} / \mathrm{kg})$ of Roselle extract was inadequate to produce significant reduction in AST level compared to the INH-RIF group. Figure 2 also shows that the liver MDA level of the INHRIF group was extremely elevated compared to the control's MDA level $(P<0.05)$. This marked elevation of liver MDA level was experienced by all INH-RIF-treated rats, with the concentration of at least three times of the average MDA levels of the normal rats. In contrast, a significant elevation of liver MDA level was not experienced by any of the Roselle extract groups. Similarly, the renal MDA level of the INH-RIF group also dramatically increased
$(P<0.05)$, which was experienced by 3 out of 5 rats in the group. Meanwhile, none of the Roselle extract-treated rats had a marked increase in renal MDA level, regardless of the difference in the amount of extract given.

Histopathological changes in liver and renal tissues Histopathological examination was carried out in this study to convey more evidence of the liver and renal injuries in the experimental rats. The representative photomicrographs of the liver tissues of the treatment groups are illustrated in Figure 3. The control rats displayed a typical architecture of healthy hepatocytes separated by sinusoids. The hepatocytes presented a homogenous cytoplasm and a well-defined nucleus containing nucleolus (Figure 3A). Some erythrocytes and Kupffer cells were found in the lumen of the sinusoid. In contrast, the examination of liver tissue of INH-RIF treated animals showed some alteration of liver histology (Figures $3 \mathrm{~B}$ and $3 \mathrm{C}$ ). At $\times 100$ magnification, the dilatation of sinusoid was noticeable and was accompanied by numerous infiltrations of inflammatory cells (Figure 3B). A closer observation ( $\times 400$ magnification) of the INHRIF rats' liver tissue showed a diffuse degeneration of hepatic tissue, which is characterized by disorganization of hepatocytes with missing or deformed/pyknotic nuclei as well as vacuolization (Figure 3C). Some areas also showed hepatocyte ballooning degeneration, characterized by swollen cytoplasm of the hepatocytes.

In the group treated with $62.5 \mathrm{mg} / \mathrm{kg}$ Roselle extract, the liver histology mostly showed profound histopathological changes, such as hepatocyte degeneration, deformed and pyknotic nuclei, and vacuolization, similar to that seen in the INH-RIF group (Figure 3D); yet, the number of inflammatory cells dropped compared to that of INHRIF group. Meanwhile, INH-RIF + $125 \mathrm{mg} / \mathrm{kg}$ extract and INH-RIF + $250 \mathrm{mg} / \mathrm{kg}$ groups showed a marked reduction of hepatic degeneration with a minimal number of inflammatory cells in the sinusoid. Both groups demonstrated a mild dilation of sinusoid but the lobular architecture of hepatocytes was well preserved (Figures 3E \& $3 \mathrm{~F})$.

In the renal tissue of the control rats, the histopathological changes were minimal, mostly in the form of congestion in

Table 2. The baseline levels of liver and renal biomarkers prior to treatment administration

\begin{tabular}{|c|c|c|c|c|}
\hline Groups & ALT (U/L) & AST (U/L) & Urea (mg/dL) & Creatinine $(\mathrm{mg} / \mathrm{dL})$ \\
\hline Control & $36.60 \pm 6.36$ & $86.68 \pm 10.95$ & $30.03 \pm 2.16$ & $0.408 \pm 0.010$ \\
\hline INH-RIF & $38.97 \pm 7.90$ & $96.09 \pm 13.23$ & $26.65 \pm 6.37$ & $0.409 \pm 0.028$ \\
\hline Roselle 62.5 + INH-RIF & $27.60 \pm 7.04$ & $56.79 \pm 9.89$ & $23.71 \pm 2.30$ & $0.276 \pm 0.041$ \\
\hline Roselle 125 + INH-RIF & $40.22 \pm 4.73$ & $84.45 \pm 11.10$ & $28.94 \pm 1.73$ & $0.428 \pm 0.033$ \\
\hline Roselle 250 + INH-RIF & $44.41 \pm 7.94$ & $97.60 \pm 13.84$ & $31.42 \pm 1.81$ & $0.358 \pm 0.057$ \\
\hline
\end{tabular}

Data is expressed as mean \pm SEM. All groups did not show significant differences in baseline biomarker levels. ALT: alanine aminotransferase; AST: aspartate aminotransferase; INH-RIF: isoniazid-rifampicin combination 

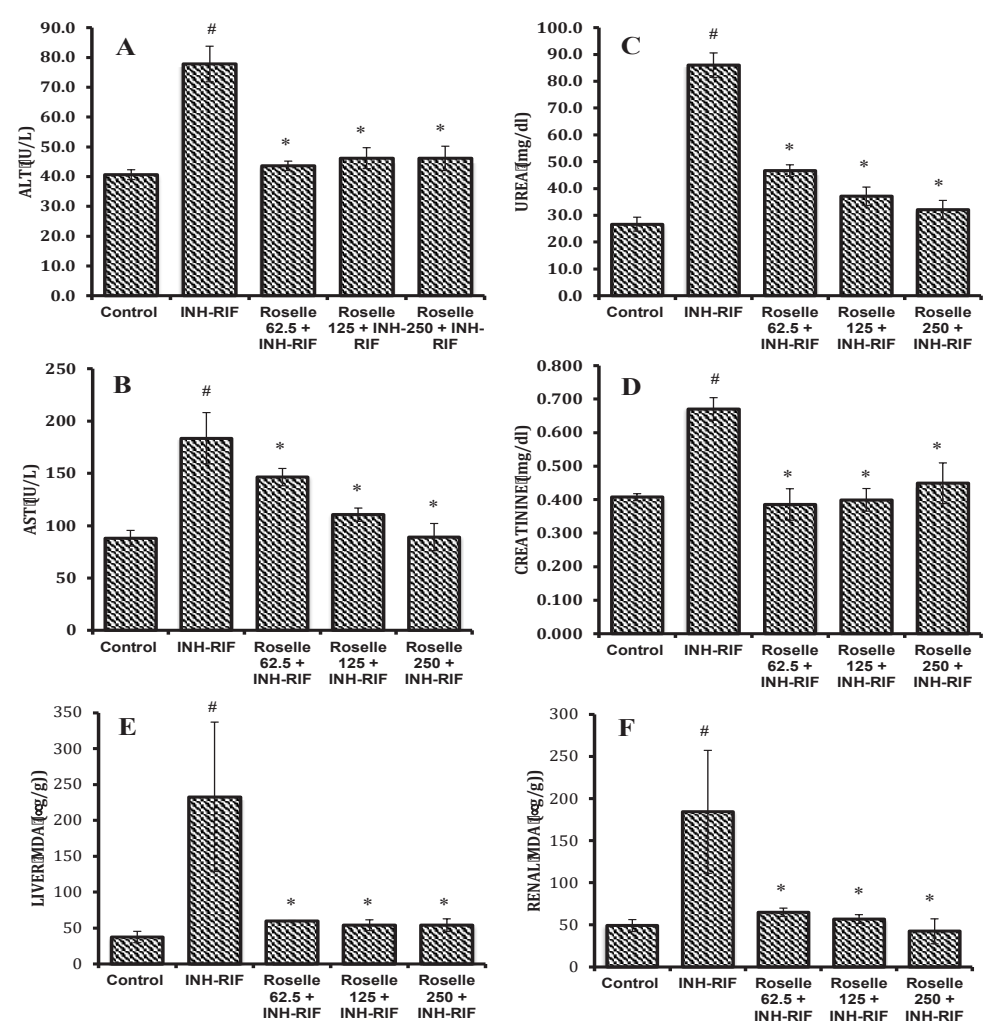

Figure 2. The comparison of serum alanine aminotransaminase (ALT) (A), aspartate aminotransferase (AST) (B), urea (C), creatinine (D), liver malondialdehyde $(E)$ and renal malondialdehyde $(F)$ levels among groups following 6 weeks of treatment. Data is expressed in mean $\pm S E M$. ${ }^{*} P<0.05$ compared to normal control. ${ }^{*} P<0.05$ compared to INH-RIF group.

renal blood vessels. Other than that, the renal tissue of the control rats presented normal appearances of glomeruli and tubules (Figure 4A).

Treating animals with INH-RIF for 6 weeks caused various histological alterations. One of the main features was the presence of inflammatory cell infiltrations that were widely spread in the large area of intertubular tissue (Figure 4B). The signs of tubular degeneration were prominent, shown by denudation of the renal tubular cells, dilation of lumen tubules, and intraluminal proteinaceous casts (Figure 4C). Distortion of the renal architecture was still evident in the group pretreated with Roselle extract at a low dose $(62.5 \mathrm{mg} / \mathrm{kg})$, wherein the tubular degeneration and granular casts were found scattered throughout the renal tissue area (Figure 4D). In the Roselle $125 \mathrm{mg} / \mathrm{kg}+$ INH-RIF group, a certain degree of tubular degeneration and intratubular cast formation was still observed (Figure 4E). Meanwhile, increasing the Roselle water extract dose to $250 \mathrm{mg} / \mathrm{kg}$ was found to ameliorate most histopathological alteration that was observed in the Roselle $125 \mathrm{mg} / \mathrm{kg}$ + INH-RIF group (Figure 4F).

Liver and renal histopathologic scores

The degree of histopathological abnormalities was scored to denote the numerical values of the severity of the lesion observed (Table 3). In the control group, the histopathological changes found in the liver and renal tissues were mostly minimal (appeared in $0-10 \%$ of the observed area). In contrast, in the INH-RIF group, histopathological alterations (tissue degeneration, deformed nuclei, necrotic cells, hemorrhage and infiltration of leukocytes) were found in $>40 \%$ of the hepatic and renal tissue sections (scored as marked). Abnormal structures of the liver and renal tissues in the group treated with $62.5 \mathrm{mg} / \mathrm{kg}$ Roselle extract were still evident in several rats (scored as marked), although two out of the five rats had slightly improved liver and renal damage (scored as moderate). With a higher dose of Roselle extract $(125 \mathrm{mg} / \mathrm{kg})$, the intensity of the liver and renal tissue damage was reduced, which only affected 20 $40 \%$ of the observed tissue regions (scored as moderate to mild). Meanwhile, pre-treatment with $250 \mathrm{mg} / \mathrm{kg}$ of Roselle extract was found to significantly reduce the liver and renal injuries, and led to a near-normal architecture of the liver and renal tissues (scored as mild to minimal).

\section{Discussion}

INH and RIF are among drugs that have been extensively used to create a drug-induced hepatotoxicity model in rats. INH and RIF can be used in a fixed-dose combination of AT to induce liver and renal damage for 28 days $(26,27)$, but the most common dose of INH-RIF used in experimental 


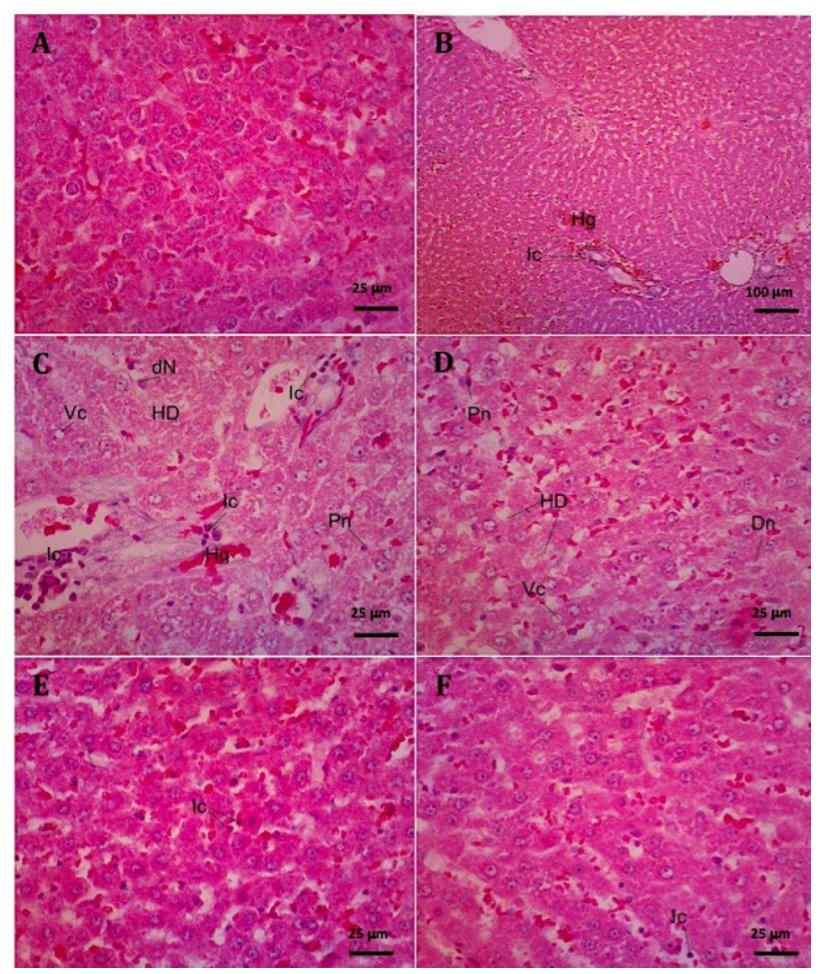

Figure 3. The representative of liver photomicrographs of the control (A), INH-RIF (B and C), Roselle 62.5 + INH-RIF (D), Roselle $125+$ INH-RIF (E), Roselle 250 + INH-RIF (F) groups. HD: Hepatocyte degeneration; Dn: deformed nuclei; Vc: vacuolization; Pn: pyknotic nuclei; Hg: hemorrhage; Ic: inflammatory cell infiltration.

models of hepatotoxicity is $50 \mathrm{mg} / \mathrm{kg} /$ day for each drug (28), or $50 \mathrm{mg} / \mathrm{kg}$ INH and $100 \mathrm{mg} / \mathrm{kg}$ RIF (19). However, in this study, a higher dose of INH-RIF with a longer duration of treatment was required to sufficiently evoke hepatotoxicity in the animals. The dose of INH-RIF was increased to $100 \mathrm{mg} / \mathrm{kg}$ for INH and $200 \mathrm{mg} / \mathrm{kg}$ for RIF, and the duration was prolonged until 42 days. With this given dose, the indication of hepatotoxicity was evident, where the serum levels of liver transaminase escalated at least two times from their baseline values in INH-RIF treated rats. The rise of transaminase enzymes was also accompanied by augmentation of serum creatinine and urea levels, suggesting an abnormal renal function in rats after 42 days of INH-RIF treatment.

The elevation of serum biomarkers was accompanied by a substantial increase in the concentrations of liver and renal MDA, an indicator of lipid peroxidation, which is

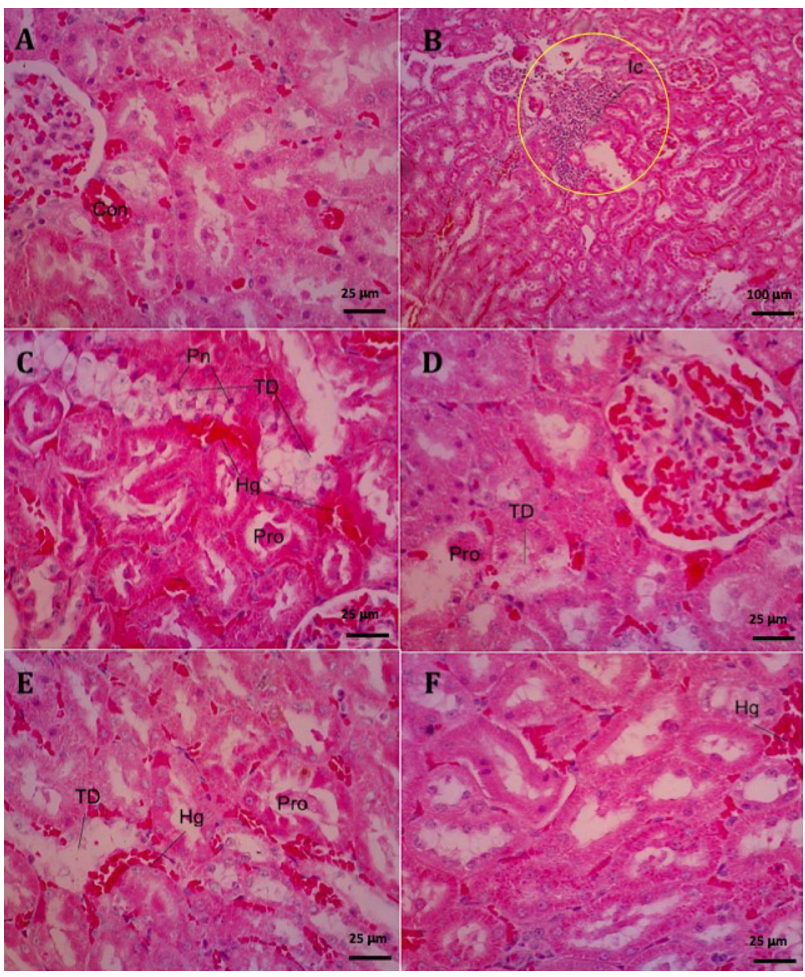

Figure 4. The representative of liver photomicrographs of the control (A), INH-RIF (B and C), Roselle 62.5 + INH-RIF (D), Roselle $125+$ INH-RIF (E), Roselle $250+$ INH-RIF (F) groups. Con: congestion; TD: tubular degeneration; Pro: proteinaceous cast, $\mathrm{Hg}$ : hemorrhage; Ic: inflammatory cell infiltration (yellow circle).

most likely to rise in the presence of cellular oxidative damage (29). This result has been anticipated since the mechanisms of INH-RIF-induced organ damage are associated with oxidative stress triggered by their active metabolites (24). In addition, compiling evidence has demonstrated that INH-RIF administration also reduces endogenous antioxidant enzymes, including glutathione, superoxide dismutase, and catalase, leading to insufficient cellular defense systems to protect from cellular injuries $(30,31)$.

It is believed that the antioxidant content of Roselle extract has mediated its protection against INH-RIFinduced organ damage. Several investigations have revealed that the antioxidant capacity of Roselle extract was more potent compared to the typical antioxidants, such as butylated hydroxy-anisole and $\alpha$-tocopherol (32). Supporting this, the administration of Roselle extracts

Table 3. The degree of histopathological changes found in the liver and renal tissues following 6 weeks of treatments

\begin{tabular}{lllllll}
\hline & Histopathological Changes & Control & INH-RIF & Roselle 62.5 + INH-RIF & Roselle 125 + INH-RIF & Roselle 250 + INH-RIF \\
\hline Liver & Hb, HD, Dn, Pn, Hg, Ic & + & ++++ & $+++/+++$ & $++/+++$ & ++ \\
Kidney & TD, Con, Pro, Hg, Ic & + & ++++ & $+++/+++$ & +++ & $+/++$ \\
\hline
\end{tabular}

$\mathrm{Hb}=$ Hepatocyte ballooning, $\mathrm{HD}=$ hepatocyte degeneration; $\mathrm{Dn}=$ deformed nuclei; $\mathrm{Pn}=$ pycnotic nuclei; $\mathrm{Hg}=$ hemorrhage; Ic=Inflammatory cell infiltration; TD=tubular degeneration; Con=congestion; Pro= proteinaceous cast in lumen tubuli. The degree of histopathological changes was minimal $(+)$, mild $(++)$, moderate $(+++)$, or marked $(++++)$. 
in this study has appeared to improve the liver and renal injury biomarkers in the rats. Pre-treatment with $125 \mathrm{mg} /$ $\mathrm{kg}$ or $250 \mathrm{mg} / \mathrm{kg}$ of Roselle water extract prior to INHRIF treatment was able to retain the normal levels of ALT, AST, urea, creatinine, and tissue MDA $(P<0.05)$. The histological findings revealed that both $125 \mathrm{mg} / \mathrm{kg}$ and $250 \mathrm{mg} / \mathrm{kg}$ doses of Roselle water extract significantly alleviated the hepatic degeneration induced by INH-RIF; yet, only at the high dose $(250 \mathrm{mg} / \mathrm{kg})$, Roselle extract was effective to reduce histopathological changes in the renal tissue.

\section{Limitation of the study and future direction}

The presence of liver and renal injuries can be confirmed by a range of serum biomarkers. This study only relied on the increase in the serum level of liver transaminase enzymes. However, a marked elevation of these liver enzymes has been recognized as a specific indication of the presence of hepatocellular injury (33). Similarly, the presence of renal injury was determined using serum creatinine and urea parameters only, which are often not highly sensitive to detect an acute kidney injury. Yet, these parameters have been extensively used to determine the presence of nephrotoxicity in animal models (34).

The results of the present study may find clinical relevance in TB patients. The incidences of hepatotoxicity and acute kidney injury have been demonstrated in TB patients during the course of INH and RIF therapy. The INHRIF-induced hepatotoxicity may develop as soon as two weeks from treatment initiation (35) and the onset of acute kidney injury may be present after 2 months (36). Moreover, there is evidence that Roselle extract can inhibit the growth of the multidrug-resistance Mycobacterium tuberculosis (H37rv) (37), which may offer additional benefit in TB patients.

\section{Conclusion}

It is concluded that Roselle calyx extract can provide protection against liver and renal toxicities induced by INH-RIF administration in rats. The use of natural exogenous antioxidants such as those contained in the Roselle calyces might become an important approach to reduce stress oxidative imposed by AT drugs. Further research is warranted to support the use of Roselle water extract to potentially reduce the risk of organ injury or dysfunction in patients receiving AT drugs.

\section{Acknowledgments}

The authors wish to thank Dr. Mufidah for her valuable advice and support during the course of the experiment.

\section{Authors' contributions}

YYD contributed in research concept and methodological design, manuscript writing, and data interpretation. JA, NA and NR conducted the experiments and data analysis; SS, SSM and UU contributed in data analysis, interpretation and manuscript revision.

\section{Conflict of interests}

The authors declare to have no conflict of interest

\section{Ethical considerations}

All animal protocols complied with the guide for the care and use of laboratory animals and had been granted an ethical clearance number of UH18010001 from the institutional ethics committee under the Faculty of Medicine, Hasanuddin University.

\section{Funding/Support}

The authors received no specific funding for this research

\section{References}

1. Anwar H, Hussain G, Mustafa I. Antioxidants from natural sources. In: Shalaby E, Azzam GM, eds. Antioxidants in Foods and its Applications. London, UK: IntechOpen; 2018. doi: 10.5772/intechopen.75961.

2. Abou-Arab AA, Abu-Salem FM, Abou-Arab EA. Physicochemical properties of natural pigments (anthocyanin) extracted from roselle calyces (Hibiscus subdariffa). J Am Sci. 2011;7(7):445-456.

3. Cid-Ortega S, Guerrero-Beltrán JA. Roselle calyces (Hibiscus sabdariffa), an alternative to the food and beverages industries: a review. J Food Sci Technol. 2015;52(11):685969. doi: 10.1007/s13197-015-1800-9.

4. Ahsan M, Gonsales AV, Sartini S, Wahyudin E, Nainu F. In vivo anti-staphylococcal activity of roselle (Hibiscus sabdariffa L.) calyx extract in Drosophila model of infection. J Herbmed Pharmacol. 2019;8(1):41-6. doi: 10.15171/ jhp.2019.07.

5. Hirunpanich V, Utaipat A, Morales NP, Bunyapraphatsara $\mathrm{N}$, Sato H, Herunsale A, et al. Hypocholesterolemic and antioxidant effects of aqueous extracts from the dried calyx of Hibiscus sabdariffa L. in hypercholesterolemic rats. J Ethnopharmacol. 2006;103(2):252-60. doi: 10.1016/j. jep.2005.08.033.

6. Ademiluyi AO, Oboh G. Aqueous extracts of Roselle (Hibiscus sabdariffa Linn.) varieties inhibit $\alpha$-amylase and a-glucosidase activities in vitro. J Med Food. 2013;16(1):8893. doi: 10.1089/jmf.2012.0004.

7. Ahmad-Raus R, Jamal P, Mohd-Isa ES. Hibiscus sabdariffa aqueous extracts prevents progression of acute liver injury induced by acetaminophen. Pertanika J Trop Agric Sci. 2012;35(3):511-20.

8. Liu JY, Chen CC, Wang WH, Hsu JD, Yang MY, Wang CJ. The protective effects of Hibiscus sabdariffa extract on CCl4-induced liver fibrosis in rats. Food Chem Toxicol. 2006;44(3):336-43. doi: 10.1016/j.fct.2005.08.003.

9. Carvajal-Zarrabal O, Barradas-Dermitz DM, Orta-Flores Z, Hayward-Jones PM, Nolasco-Hipólito C, AguilarUscanga MG, et al. Hibiscus sabdariffa L., roselle calyx, from ethnobotany to pharmacology. J Exp Pharmacol. 2012;4:25-39. doi: 10.2147/jep.s27974.

10. Da-Costa-Rocha I, Bonnlaender B, Sievers H, Pischel I, Heinrich M. Hibiscus sabdariffa L. - a phytochemical and pharmacological review. Food Chem. 2014;165:424-43. doi: 
10.1016/j.foodchem.2014.05.002.

11. Khoo HE, Azlan A, Tang ST, Lim SM. Anthocyanidins and anthocyanins: colored pigments as food, pharmaceutical ingredients, and the potential health benefits. Food Nutr Res. 2017;61(1):1361779. doi: 10.1080/16546628.2017.1361779.

12. Reid MJA, Arinaminpathy N, Bloom A, Bloom BR, Boehme C, Chaisson R, et al. Building a tuberculosisfree world: the Lancet Commission on tuberculosis. Lancet. 2019;393(10178):1331-84. doi: 10.1016/s01406736(19)30024-8

13. Tiberi S, Muñoz-Torrico M, Duarte R, Dalcolmo M, D’Ambrosio L, Migliori GB. New drugs and perspectives for new anti-tuberculosis regimens. Pulmonology. 2018;24(2):86-98. doi: 10.1016/j.rppnen.2017.10.009.

14. Bouazzi OE, Hammi S, Bourkadi JE, Tebaa A, Tanani DS, Soulaymani-Bencheikh R, et al. First line anti-tuberculosis induced hepatotoxicity: incidence and risk factors. Pan Afr Med J. 2016;25:167. doi: 10.11604/pamj.2016.25.167.10060.

15. Isa SE, Ebonyi AO, Shehu NY, Idoko P, Anejo-Okopi JA, Simji $\mathrm{G}$, et al. Antituberculosis drugs and hepatotoxicity among hospitalized patients in Jos, Nigeria. Int J Mycobacteriol. 2016;5(1):21-6. doi: 10.1016/j.ijmyco.2015.10.001.

16. Metushi IG, Cai P, Zhu X, Nakagawa T, Uetrecht JP. A fresh look at the mechanism of isoniazid-induced hepatotoxicity. Clin Pharmacol Ther. 2011;89(6):911-4. doi: 10.1038/ clpt.2010.355.

17. Ramappa V, Aithal GP. Hepatotoxicity related to antituberculosis drugs: mechanisms and management. J Clin Exp Hepatol. 2013;3(1):37-49. doi: 10.1016/j. jceh.2012.12.001.

18. Eminzade S, Uraz F, Izzettin FV. Silymarin protects liver against toxic effects of anti-tuberculosis drugs in experimental animals. Nutr Metab (Lond). 2008;5:18. doi: 10.1186/1743-7075-5-18.

19. Shih TY, Young TH, Lee HS, Hsieh CB, Hu OY. Protective effects of kaempferol on isoniazid- and rifampicin-induced hepatotoxicity. AAPS J. 2013;15(3):753-62. doi: 10.1208/ s12248-013-9490-6.

20. Muzika V, Čustović S, Mornjaković Z, Ćosović E, Kapić D. Histological study of isoniazid-rifampicin related nephrotoxicity in Wistar rats. Folia Med Fac Med Univ Saraev. 2016;51(1):4-9.

21. Hussein OE, Germoush MO, Mahmoud AM. Ruta graveolens protects against isoniazid/rifampicin-induced nephrotoxicity through modulation of oxidative stress and inflammation. Glob J Biotechnol Biomater Sci. 2016;1(1):17-22.

22. Harbourne N, Jacquier JC, O'Riordan D. Optimisation of the aqueous extraction conditions of phenols from meadowsweet (Filipendula ulmaria L.) for incorporation into beverages. Food Chem. 2009;116(3):722-7. doi: 10.1016/j.foodchem.2009.03.017.

23. Archaina D, Vasile F, Jiménez-Guzmán J, AlamillaBeltrán L, Schebor C. Physical and functional properties of roselle (Hibiscus sabdariffa L.) extract spray dried with maltodextrin-gum Arabic mixtures. J Food Process Preserv. 2019;43(9):e14065. doi: 10.1111/jfpp.14065.

24. Chowdhury A, Santra A, Bhattacharjee K, Ghatak S,
Saha DR, Dhali GK. Mitochondrial oxidative stress and permeability transition in isoniazid and rifampicin induced liver injury in mice. J Hepatol. 2006;45(1):117-26. doi: 10.1016/j.jhep.2006.01.027.

25. Shackelford C, Long G, Wolf J, Okerberg C, Herbert R. Qualitative and quantitative analysis of nonneoplastic lesions in toxicology studies. Toxicol Pathol. 2002;30(1):936. doi: 10.1080/01926230252824761.

26. Djabir YY, Arsyad A, Usmar U, Wahyudin E, Arwi H, Rupang IS. The stages of development of liver and renal injuries in rats induced by fixed dose combination of antituberculosis regimen. FABAD J Pharm Sci. 2020;45(1):29-35.

27. Djabir YY, Arsyad A, Murdifin M, Tayeb R, Amir MN, Kamaruddin FA, et al. Kleinhovia hospita extract alleviates experimental hepatic and renal toxicities induced by a combination of antituberculosis drugs. J Herbmed Pharmacol. 2021;10(1):102-8. doi: 10.34172/jhp.2021.10.

28. Rana SV, Pal R, Vaiphie K, Singh K. Effect of different oral doses of isoniazid-rifampicin in rats. Mol Cell Biochem. 2006;289(1-2):39-47. doi: 10.1007/s11010-006-9145-3.

29. Ayala A, Muñoz MF, Argüelles S. Lipid peroxidation: production, metabolism, and signaling mechanisms of malondialdehyde and 4-hydroxy-2-nonenal. Oxid Med Cell Longev. 2014;2014:360438. doi: 10.1155/2014/360438.

30. Attri S, Rana SV, Vaiphei K, Sodhi CP, Katyal R, Goel RC, et al. Isoniazid- and rifampicin-induced oxidative hepatic injury--protection by $\mathrm{N}$-acetylcysteine. Hum Exp Toxicol. 2000;19(9):517-22. doi: 10.1191/096032700674230830.

31. Mujahid M, Hussain T, Siddiqui HH, Hussain A. Evaluation of hepatoprotective potential of Erythrina indica leaves against antitubercular drugs induced hepatotoxicity in experimental rats. J Ayurveda Integr Med. 2017;8(1):7-12. doi: $10.1016 /$ j.jaim.2016.10.005.

32. Tee PL, Yusof S, Mohamed S. Antioxidative properties of roselle (Hibiscus sabdariffa L.) in linoleic acid model system. Nutr Food Sci. 2002;32(1):17-20. doi: $10.1108 / 00346650210413951$.

33. Amacher DE. Serum transaminase elevations as indicators of hepatic injury following the administration of drugs. Regul Toxicol Pharmacol. 1998;27(2):119-30. doi: 10.1006/ rtph.1998.1201.

34. Stonard M. Assessment of nephrotoxicity. In: Evans GO, ed. Animal Clinical Chemistry: A Primer for Toxicologists. London: Taylor \& Francis Ltd; 1996. p. 83-94.

35. Makhlouf HA, Helmy A, Fawzy E, El-Attar M, Rashed HA. A prospective study of antituberculous drug-induced hepatotoxicity in an area endemic for liver diseases. Hepatol Int. 2008;2(3):353-60. doi: 10.1007/s12072-008-9085-y.

36. Chang $\mathrm{CH}$, Chen YF, Wu VC, Shu CC, Lee CH, Wang JY, et al. Acute kidney injury due to anti-tuberculosis drugs: a five-year experience in an aging population. BMC Infect Dis. 2014;14:23. doi: 10.1186/1471-2334-14-23.

37. Djide NJ, Djide MN, Amir MN, Sartini S. Antibacterial activity of rosella calyx extract encapsulated by maltodextrin and its sinergity with isoniazid and rifampicin against Mycobacterium tuberculosis h37rv. Galenika J Pharm. 2019;5(2):117-23. doi: 10.22487/j24428744.2019. v5.i2.12946. 